\title{
PENGARUH PERBEDAAN UKURAN MATA PANCING TERHADAP HASIL TANGKAPAN RAWAI DASAR DI PERAIRAN PENGAMBENGAN
}

\author{
THE EFFECT OF HOOK SIZE DIFFERENCE ON THE BOTTOM LONG LINE \\ CATCHES IN PENGAMBENGAN WATERS
}

\author{
Faris Putra Pratama ${ }^{1}$, Untung Prasetyono ${ }^{1 *}$, Deni Sarianto ${ }^{2}$ \\ ${ }^{1}$ Politeknik Kelautan dan Perikanan Karawang, Jalan Lingkar Tanjungpura, Karangpawitan, Kecamatan \\ Karawang Barat, Kabupaten Karawang, Jawa Barat 41315 \\ ${ }^{2}$ Politeknik Kelautan dan Perikanan Maluku, Jl. Laksdya Leo Wattimena No.KM, RW.16, Waiheru, \\ Baguala, Kota Ambon, Maluku 97612
}

Teregistrasi I tanggal: 27 Juli 2020; Diterima setelah perbaikan tanggal: 29 September 2020; Disetujui terbit tanggal: 29 September 2020

\begin{abstract}
ABSTRAK
Rawai dasar sampai saat ini dianggap sebagai alat tangkap yang paling efektif digunakan untuk menangkap ikan demersal. Penelitian bertujuan untuk mengetahui perbedaan ukuran mata pancing dan komposisi hasil tangkapan dari dua ukuran mata pancing yang berbeda. Pengoperasian alat tangkap dengan menggunakan 2 macam ukuran mata pancing yaitu nomor 7 dan nomor 9 yang dioperasikan secara bersamaan. Lokasi penelitian di perairan pengambengan Bali. Hasil tangkapan yang diperoleh menunjukan tidak berbeda nyata, namun terdapat kecenderungan mata pancing yang berukuran kecil nomor 7 lebih efektif dibanding mata pancing yang lebih besar nomor 9. Hasil tangkapan yang relatif banyak diperoleh dengan rawai dasar yang dioperasikan di perairan yang agak-dalam dengan hasil tangkapan lebih besar ukurannya. Jenis ikan ekonomis penting yang banyak tertangkap selama pengoperasian rawai dasar adalah Lutjanus analis (Kakap Domba), Caranx sexfaciatus (Kuwe Putih), Lutjanus campechanus (Kakap Merah), dan Plectropomus leopardus (Kerapu Sunu). Ukuran ikan yang tertangkap diduga tidak hanya dipengaruhi oleh ukuran mata pancing tetapi juga oleh faktor lain diantaranya ukuran umpan, dan jenis umpan yang digunakan, musim, dan faktor lingkungan perairan.
\end{abstract}

Kata kunci: demersal, keberlanjutan perikanan, perikanan tangkap, alat tangkap ikan

\begin{abstract}
Bottom longlines have been considered as the most effective fishing gears until now to catch demersal fish. The objective of this research is to analyze the effect of hook size difference on the catch composition of bottom longlines. Two types of hook size are used in this research which are number 7 and 9. The results show that when the two types of hook size are operated at the same time, the catch is not significant difference. However, the small one (number 7) is more effective than the big one (number 9). The bottom longlines which are operated in a deep perwatero btain high catch with bigger size fish. The most high economic value of fish caught during this study are Lutjanus analis, Caranx sexfaciatus, Lutjanus campechanus, and Plectropomus leopardus. This study also finds that the size of fish caught is not determined by hook size, but it is determined by the size of bait and type of bait used.
\end{abstract}

Keywords: demersal, sustainability fisheries, capture fisheries, fishing gear

Korespondensi penulis:
*Email: untungprasetyono@yahoo.com

DOI: http://dx.doi.org/10.15578/plgc.v1i3.9167 


\section{PENDAHULUAN}

Perairan Pengambengan Bali, merupakan salah satu wilayah strategis sebagai daerah perikanan dan memiliki potensi besar untuk pengembangan sektor perikanan tangkap. Banyak jenis alat tangkap yang digunakan dan dioperasikan di Perairan Pengambengan. Salah satu alat tangkap yang banyak digunakan nelayan adalah rawai dasar (bottom long line). Produksi perikanan demersal yang merupakan hasil tangkapan rawai dasar di daerah ini berdasarkan data statistik tercatat sebesar 3.877 ton/tahun (DKP, 2018). Perairan Indonesia memiliki sumber daya ikan demersal yang cukup melimpah (Perangin-angin et al., 2016a; 2016b), namun demikian pengaturan alat tangkap menjadi penting untuk mendukung keberlanjutan perikanan demersal (Perangin-angin et al., 2017; 2018).

Rawai dasar merupakan alat tangkap ikan demersal. Konstruksinya sederhana, pengoperasian- nya juga tidak memerlukan modal besar. Perkembangan perikanan rawai dasar tidak banyak mengalami kemajuan yang berarti jika dibandingkan dengan alat tangkap lainnya. Disisi lain dalam rangka peningkatan produksi hasil tangkapan, maka diperlukan pengembangan perikanan rawai dasar. Salah satu usaha pengembangan dilakukan dengan memodifikasi alat tangkap ikan yang sudah ada.

Rawai dasar merupakan alat tangkap sederhana dengan konstruksi ukuran dan bentuk mata pancing serta berbagai jenis umpan buatan sebagai faktor utama keberhasilan pengoperasian alat tangkap. Mata pancing (hook) merupakan bagian yang sangat vital dalam proses penangkapan ikan pada alat tangkap pancing (Wudianto et al., 2017). Mata pancing mempunyai bentuk dan ukuran yang berbeda-beda dan sangat berpengaruh terhadap ukuran ikan sasaran. Oleh karena itu pengembangan alat tangkap ini dilakukan dengan berbagai uji coba dan modifikasi guna mendapatkan informasi baru terkait ukuran dan bentuk mata pancing. Modifikasi alat tangkap melalui penelitian uji coba pada pengoperasian alat tangkap rawai dasar telah dilakukan oleh beberapa peneliti, antara lain (Wudianto et al., 2017) tentang pengaruh perbedaan ukuran mata pancing pada usaha perikanan karang. Kemudian penelitian Siswoko et al. (2013) di perairan Pacitan tentang pengaruh perbedaan jenis umpan dan mata pancing terhadap hasil tangkapan pancing ulur (hand line). Lebih lanjut hasil penelitian Amirulloh \& Bambang (2014) tentang pengaruh jenis dan ukuran mata pancing terhadap hasil tangkapan rawai; Kurnia \& Yusuf (2015) tentang selektivitas ukuran mata pancing pada perikanan hand line.

Hasil-hasil penelitian tersebut menunjukkan perbedaan jenis dan ukuran mata pancing berpengaruh terhadap jumlah hasil tangkapan. Disisi lain penggunaan mata pancing dengan berbagai ukuran serta berbagai macam dan bentuk umpan buatan untuk efektivitas penangkapan ikan masih kurang diterapkan, khususnya di lokasi penelitian. Nelayan pancing rawai dasar hanya menggunakan satu ukuran mata pancing pada aktivitas penangkapan ikan. Sementara tuntutan untuk mendapatkan hasil tangkapan yang maksimal cukup tinggi. Nelayan tidak memikirkan bahwa sering terlepasnya ikan hasil tangkapan dari mata pancing atau ikan tidak terkait pada mata pancing adalah satu faktor yang menyebabkan hasil tangkapan kurang. Kegagalan pemancingan yang dilakukan tidak terpikir dan dianggap hal yang biasa.

Jadi, berdasarkan hal-hal tersebut di atas, maka penulis tertarik melakukan penelitian lanjutan untuk melihat pengaruh perbedaan ukuran mata pancing terhadap hasil tangkapan yang tertangkap dengan rawai dasar. Penelitian mengenai ke-efektifan satu ukuran mata pancing perlu dilakukan agar dapat menjadi 
informasi baru dalam pengembangan teknologi penangkapan ikan khususnya rawai dasar. Tujuan dari penelitian ini adalah untuk mengetahui pengaruh perbedaan ukuran mata pancing dan

\section{BAHAN DAN METODE}

Waktu dan Tempat

Penelitian ini dilaksanakan pada tanggal 11 Maret sampai dengan 29 Juni 2019 berlokasi di perairan Samudera Hindia dan Selat Bali yang merupakan Wilayah Pengelolaan Perikanan Republik Indonesia (WPP-NRI 713).

\section{Pengumpulan dan Analisis Data}

Konstruksi rawai dasar yang digunakan dalam praktik ini terdiri dari tali utama (main line), tali cabang (branch line), mata pancing nomor 7 dan 9, pemberat dan pelampung tanda. Masing masing alat tangkap menggunakan mata pancing berjumlah 200 buah dengan panjang tali utama $1050 \mathrm{~m}$, Monofilament berdiameter 3,0 $\mathrm{mm}$. Tali utama berfungsi sebagai tempat menaruh tali cabang. Panjang tali cabang $150 \mathrm{~cm}$, Monofilament berdiameter 1,2 $\mathrm{mm}$. Adapun spesifikasi dari masing-masing ukuran mata pancing yang digunakan seperti pada Gambar 2.

Untuk mengoperasikan rawai dasar digunakan perahu kayu berukuran panjang $8,2 \mathrm{~m}$, lebar $1,6 \mathrm{~m}$, dan dalam $0,5 \mathrm{~m}$ dengan dilengkapi mesin dalam berkekuatan 10,5 HP. Jumlah tenaga yang diperlukan untuk mengoperasikan rawai dasar sebanyak 4-5 orang. Sebagai bahan penarik ikan sasaran agar mau memakan pancing digunakan umpan berupa ikan segar. Beberapa jenis ikan umpan yang digunakan adalah ikan lemuru, kembung dan tongkol. Bagi ikan yang berukuran kecil seperti lemuru digunakan masih dalam keadaan utuh sedangkan ikan umpan yang besar dipotong menjadi ukuran antara 50-100 gram.

Rawai dasar dioperasikan di perairan karang Wilayah Pengelolaan komposisi hasil tangkapan dari dua ukuran mata pancing yang berbeda sehingga diperoleh ukuran mata pancing yang efektif.

Perikanan Republik Indonesia (WPPNRI) 573 Samudera Hindia dan Selat Bali. Alat tangkap dioperasikan pada kedalaman antara 20-30 m pada waktu malam hari. Lama pancing di dalam air / drifting berkisar antara 30-40 menit. Kedua ukuran mata pancing diturunkan bersamaan. Jumlah mata pancing yang dioperasikan 200 mata untuk masingmasing ukuran mata pancing. Untuk mengetahui kemampuan rawai dasar dalam menangkap ikan digunakan "hook rate" (laju pancing) yaitu banyaknya ikan yang tertangkap oleh 200 mata pancing yang digunakan.

Rumus yang digunakan untuk menghitung hook rate sebagai berikut:

$$
H R=\frac{I}{R} x 100
$$

Keterangan:

$\mathrm{HR}=$ Hook Rate

$\mathrm{I}=$ Jumlah ikan yang tertangkap (ekor)

$\mathrm{R}=$ Jumlah mata pancing yang digunakan selama operasi (mata pancing)

Hasil tangkapan yang diperoleh dari pengoperasian rawai dasar setiap stasiun penangkapan, diidentifikasi jenisnya kemudian dipisahkan berdasarkan jenis ikan untuk masing-masing ukuran mata pancing yang digunakan. Ikan yang tertangkap kemudian diukur berat maupun panjangnya. Untuk mengetahui produktivitas masing-masing ukuran mata pancing, dilakukan uji normalitas terhadap ukuran mata pancing (Maspeke et al., 2019). Jenis ikan yang dominan tertangkap dan mempunyai nilai ekonomis penting diukur panjang totalnya kemudian dikelompokkan berdasarkan ukuran mata pancing untuk mengetahui adanya hubungan antara ukuran mata pancing dan besar ikan yang tertangkap. 
HASIL DAN BAHASAN HASIL

Hasil tangkapan rawai dasar pada masing-masing stasiun penangkapan yang dinyatakan dalam hook rate (laju pancing) berdasarkan ukuran mata pancing di perairan disajikan pada Tabel 1 dan 2 .

Dari Tabel tersebut diperoleh laju pancing rawai dasar yang dioperasikan di perairan Pengambengan untuk setiap ukuran mata pancing adalah mata pancing nomor 7 memperoleh tangkapan sebanyak 31 ekor dengan tangkapan dominan ikan kakap domba sebanyak 19 ekor. Mata pancing nomor 9 memperoleh hasil tangkapan sebanyak 16 ekor dengan tangkapan dominan ikan kakap domba sebanyak 7 ekor. Hasil tangkapan minimal mata pancing nomor 7 antara lain ikan Pari dan Kampuh, masing-masing sebanyak 1 ekor. Untuk mata pancing nomor 9, hasil tangkapan minimal adalah ikan Kampuh sebanyak 1 ekor.
Hasil tangkapan rawai dasar menggunakan pancing nomor 7 memiliki nilai laju mata pancing (hook rate) sebesar 0,15 ; sedangkan hasil tangkapan pada pancing nomor 9 memiliki nilai laju mata pancing (hook rate) sebesar 0,08. Rawai dasar yang menggunakan pancing nomor 7 mendapatkan hasil tangkapan lebih banyak dari pada rawai dasar yang menggunakan pancing nomor 9 .

Hasil uji normalitas One Sample Kolmogrov-Smirnov terhadap jumlah berat hasil tangkapan dan total hasil tangkapan rawai dasar yang diberi perlakuan alat tangkapan modifikasi dan tidak modifikasi berturut turut sesuai Tabel 3 dan Tabel 4.

Berdasarkan Tabel 3 hasil output SPSS uji normalitas kolmogorov-smirnov analisa sebaran berat ikan terhadap jumlah ikan dengan menggunakan rawai dasar modifikasi diperoleh nilai signifikansi Asiymp.Sig (2-tailed) sebesar 0,096, sedangkan Tabel 4 uji normalitas

Tabel 1. Komposisi hasil tangkapan rawai dasar menggunakan pancing no. 7

Table 1. The composition of the bottom longline catch using hook number 7

\begin{tabular}{|c|c|c|}
\hline Nama Ikan & Jumlah (Ekor) & Persentase $(\%)$ \\
\hline Kakap domba ( Lutjanus analis ) & 19 & 60 \\
\hline Kuwe ( Caranx sexfaciatus) & 2 & 7 \\
\hline Kakap merah ( Lutjanus campechanus ) & 3 & 10 \\
\hline Kerapu sunu ( Plectropomus leopardus ) & 3 & 10 \\
\hline Pari ( Dasyatidae) & 1 & 3 \\
\hline Kampuh & 1 & 3 \\
\hline Red bigeye ( Priacanthus macracanthus ) & 2 & 7 \\
\hline Jumlah & 31 & 100 \\
\hline
\end{tabular}

Tabel 2. Komposisi hasil tangkapan rawai dasar menggunakan pancing no. 9

Table 2. The composition of the bottom longline catch using hook number 9

\begin{tabular}{|c|c|c|}
\hline Nama Ikan & Jumlah (Ekor) & Persentase (\%) \\
\hline Kakap domba ( Lutjanus analis) & 7 & 44 \\
\hline Bigeye trevally ( Caranx sexfaciatus) & 2 & 12 \\
\hline Kakap merah ( Lutjanus campechanus ) & 4 & 26 \\
\hline Kerapu sunu ( Plectropomus leopardus ) & 2 & 12 \\
\hline Kampuh & 1 & 6 \\
\hline Jumlah & 16 & 100 \\
\hline
\end{tabular}


Tabel 3. One-sample kolmogorov-smirnov test menggunakan pancing no. 7 Table 3. One-sample kolmogorov-smirnov test using hook number 7

\begin{tabular}{|c|c|c|}
\hline \multicolumn{3}{|c|}{ Unstandardized Residual } \\
\hline $\mathrm{N}$ & & 20 \\
\hline \multirow[t]{3}{*}{ Normal Parameters ${ }^{\mathrm{a}, \mathrm{b}}$} & Mean &, 0000000 \\
\hline & Std. & \\
\hline & Deviation & ,26037918 \\
\hline \multirow[t]{3}{*}{ Most Extreme Differences } & Absolute &, 178 \\
\hline & Positive & 178 \\
\hline & Negative &,- 102 \\
\hline Test Statistic & &, 178 \\
\hline Asymp. Sig. (2-tailed) & &, 096 \\
\hline
\end{tabular}

a. Test distribution is Normal.

b. Calculated from data.

Tabel 4. One-sample kolmogorov-smirnov test rawai menggunakan pancing no. 9 Table 4. One-sample kolmogorov-smirnov test longline using hook number 9

\begin{tabular}{|c|c|c|}
\hline \multicolumn{3}{|c|}{ Unstandardized Residual } \\
\hline $\mathrm{N}$ & & 11 \\
\hline \multirow{3}{*}{ Normal Parameters ${ }^{\mathrm{a}, \mathrm{b}}$} & Mean &, 0000000 \\
\hline & Std. & \\
\hline & Deviation &, 59164452 \\
\hline \multirow[t]{3}{*}{ Most Extreme Differences } & Absolute &, 245 \\
\hline & Positive & 245 \\
\hline & Negative &,- 121 \\
\hline Test Statistic & & 245 \\
\hline Asymp. Sig. (2-tailed) & & ,063 \\
\hline
\end{tabular}

a. Test distribution is Normal.

b. Calculated from data.

kolmogorov-smirnov analisa sebaran berat ikan terhadap jumlah ikan dengan menggunakan rawai dasar tidak modifikasi diperoleh nilai signifikansi Asiymp.Sig (2-tailed) sebesar 0,063. Dari data tersebut menunjukkan bahwa nilai $\mathrm{sig}$ $>\propto=0,05(5 \%)$. Sesuai dengan dasar pengambilan keputusan dalam uji normalitas kolmogorov-smirnov, dapat disimpulkan bahwa data berdistribusi normal. Dengan demikian, asumsi normalitas dalam model regresi terpenuhi.

\section{BAHASAN}

Rawai dasar mempunyai kontruksi yang sangat sederhana, terdiri dari tali utama (main line), tali cabang (branch line), mata pancing (hook), pemberat, dan pelampung. Tali utama secara berderet pada jarak tertentu digantungkan tali cabang yamg ujungnya di beri mata pancing. Jumlah tali cabang yang digunakan tergantung dari kesangupan nelayan dalam menoperasikan alat tangkap. Faktor penting selain alat tangkap yang cukup memberi pengaruh dalam penangkapan ikan mengunakan rawai dasar adalah umpan (Adityarini \& Wibowo, 2012; Barata et al., 2016). Alat tangkap ini disebut rawai dasar karena alat tangkap ini sewaktu dioperasikan berbentuk rawe-rawe (rawe dalam bahasa Jawa) yang berarti sesuatu yang ujungnya bergerak bebas.

Berdasarkan Tabel 1 dan 2 diatas menunjukkan bahwa jumlah hasil tangkapan selama dua kali pengulangan, rawai dasar dangan pancing nomor 7 mendapatkan hasil yang lebih baik dari pada rawai dasar yang menggunakan pancing nomor 9. Keefektifan rawai dasar modifikasi disebabkan dengan penambahan kili-kili pada tali utama 
sehingga tali cabang tidak banyak yang putus. Hal ini senada dengan pernyataan (Alfarizi, 2015) bahwa kili-kili akan mengurangi belitan pada tali ketika ditarik oleh ikan. Selain itu ukuran mata pancing nomor 7 sangat cocok dengan ukuran bukaan mulut ikan yang tertangkap pada perairan Selat Bali. Sehingga ketika umpan dimakan oleh ikan, mata pancing nomor 7 memiliki kemungkinan besar untuk mengait pada mulut ikan karena mata pancing nomor 7 memiliki ukuran batang (shank) yang lebih panjang akan memiliki ruang gerak yang sempit pada mulut ikan dan sesuai dengan ukuran ikan disana, sehingga mulut yang memakan mata pancing nomor 7 agar dapat langsung terkait. Pralamnita \& Putra (2017), menyatakan laju penangkapan sangat di pengaruhi oleh musim; Yuliana et al. (2016) menyatakan laju penangkapan di pengaruhi oleh stok ikan di perairan; dan Sarianto et al. (2017) menyatakan kondisi lingkungan perairan sangat berpengaruh terdapat jumlah ikan pada suatu daerah penangkapan.

Rawai dasar yang mempunyai mata pancing nomor 9, memiliki ukuran lebih besar dari pada mata pancing nomor 7 , dengan ruang gerak yang lebih luas pada mulut ikan untuk ukuran ikan yang sama, sehingga kemungkinan lolos dari mulut ikan hasil tangkapan lebih besar. Meskipun mata pancing nomor 9 dapat menangkap ikan yang memiliki bukaan mulut yang besar, tetapi karena ukuran pancingnya yang besar, sering kali mata pancing tersebut tertelan ke dalam perut ikan hasil tangkapan. Hal ini menyebabkan nelayan harus merobek perut ikan untuk mengambil mata pancing. Gunarso (1985) dalam Fitri (2015) menyatakan umpan merupakan salah satu yang berpengaruh dalam penangkapan sedangkan Riyanto et al. (2017) menyatakan penciuman ikan dasar sangat berpengaruh terhadap penangkapan.

Ukuran ikan yang tertangkap tidak hanya dipengaruhi oleh ukuran mata pancing, namun juga dipengaruhi oleh beberapa faktor diantaranya bentuk umpan serta desain dari mata pancing termasuk bahan, panjang, dan jarak antara tali cabang (Brandt, 2005; Jaya et al., 2014; Muandri et al., 2013).

\section{SIMPULAN}

Hasil penelitian yang dilakukan ukuran mata pancing nomor 7 dan 9 pada pengoperasian rawai dasar menunjukkan laju tangkap yang tidak berbeda nyata, walaupun ada kecenderungan mata pancing nomor 7 memperoleh hasil tangkapan lebih tinggi dibandingkan dengan mata pancing nomor 9. Laju tangkap pancing nomor 7 juga memiliki nilai paling besar dari pada mata pancing nomor 9. Nilai laju pancing dari mata pancing nomor 7 adalah 0,15 dan mata pancing nomor 9 adalah 0,08. Nilai hook rate dinilai kurang baik karena belum mencapai nilai yang ditetapkan yaitu 1,00. Jenis ikan ekonomis yang banyak tertangkap oleh rawai dasar antara lain adalah Lutjanus analis (Kakap Domba), Caranx sexfaciatus (Kuwe Putih), Lutjanus campechanus (Kakap Merah), dan Plectropomus leopardus (Kerapu Sunu).

\section{DAFTAR PUSTAKA}

Adityarini, S., \& Wibowo, P. (2012). Pengaruh Penggunaan Perbedaan Konstruksi Mata Pancing Dan Jenis Umpan pada Pancing Ulur terhadap Hasil Tangkapan di Kawasan Zona Pemanfaatan Perikanan Tradisional Taman Nasional Karimunjawa. Journal of Fisheries Resources Utilization Management and Technology, 1(1), 97-107.

Alfarizi, M. (2015). Pengaruh Perbedaan Ukuran (Nomor) Mata Pancing Terhadap Satuan Berat Pada Hasil Tangkapan Alat Tangkap Pancing Ulur (Hand Line) Di Pelabuhan Perikanan Nusantara (Ppn) 
Brondong Lamonganjawa Timur. Disertasi. Universitas Brawijaya.

Amirulloh, R. P., \& Bambang, A. N. (2014). Perbedaan Ukuran Mata Pancing Alat Tangkap rawai Terhadap Hasil Tangkapan Yang Di Tangkap Di Perairan Srau Kabupaten Pacitan. Journal of Fisheries Resources Utilization Management and Technology, 3(2), 29-36.

Barata, A., Bahtiar, A., \& Hartaty, H. (2016). Pengaruh perbedaan umpan dan waktu setting rawai tuna terhadap hasil tangkapan tuna di Samudera Hindia. Jurnal Penelitian Perikanan Indonesia, 17(2), 133-138.

Brandt, A.V. 2005. Classification of Fishing Gear. In Kristjonson (Ed). Fishing News (Books). Ltd. London

Fitri, A. D. P. (2015). Tingkah Laku Makan Ikan Kerapu Macan (Epinephelus fuscoguttatus) terhadap Perbedaan Umpan (Skala Laboratorium). Pena Jurnal Ilmu Pengetahuan dan Teknologi, 21(1), 1-12.

Jaya, M. S. D., Pramonowibowo., \& Fitri, A. D. P. (2014). Perbedaan Jenis Umpan Dan Mata Pancing Terhadap Hasil Tangkapan Ikan Layur (Trichiurus SP) Di Perairan Lempasing, Bandar Lampung. Journal of Fisheries Resources Utilization Management and Technology, 3(4), 20-28.

Kurnia, M., \& Yusuf, M. (2015). Pengaruh Perbedaan Ukuran Mata Pancing Terhadap Hasil Tangkapan Pancing Ulur Di Perairan Pulau Sabutung Pangkep (Effects of Difference of Hook Size on the Catch of Handline in Sabutung Island Waters of Pangkep Regency). Marine Fisheries: Journal of Marine Fisheries Technology and Management, 6(1), 87-95.
Maspeke, F. I., Puspito, G., \& Solihin, I. (2019). Kombinasi Ukuran Mata Pancing dan Warna Umpan Tiruan Untuk meningkatkan Hasil Tangkapan Huhate. Jurnal Penelitian Perikanan Indonesia, 24(4), 239-251.

Muandri, N., Asriyanto, A., \& Yulianto, T. (2013). Hubungan Jenis Umpan Dan Ukuran Mata Pancing Alat Tangkap Rawai Dasar Terhadap Hasil Tangkapan Ikan Kakap (Lutjanus SP) Di Perairan Pasir, Kebumen. Journal of Fisheries Resources Utilization Management and Technology, 2(3), 82-89.

Perangin-angin R., Sulistiono, Kurnia R., Fahrudin A., \& Suman A. (2016a). Kepadatan dan Stratifikasi Komposisi Sumber Daya Ikan Demersal di Laut Cina Selatan (WPP-NRI 711), J.Lit.Perikan.Ind. 22(3), 161-172.

. (2016b). Spatial mapping: diversity and distribution of demersal fish in the Southern of South China Sea (Indonesia Fisheries Management Zone 711). International Journal of Sciences: Basic and Applied Research, 28(2), 21-33. . (2017). Struktur komunitas sumber daya ikan demersal berdasarkan kedalaman perairan di Laut Cina Selatan (WPP-NRI 711). Jurnal Iktiologi Indonesia, 17(1), 67-82.

sustainability study with sustainability window (SuWi) analysis in the South China Sea (Indonesia Fisheries Management Area 711). IOP Conference Series Earth and Environmental Science, 176, 1-10.

Pralamnita, W. A., \& Putra, I. E. (2017). Laju Tangkap dan Analisis Usaha Penangkapan Ikan Karang dengan Pancing Rawai di Perairan 
Batukaras, Jawa Barat. Jurnal

Penelitian Perikanan Indonesia, 5(2), 44-51.

Riyanto, M., Purbayanto, A., \& Wiryawan, B. (2017). Respons penciuman ikan kerapu macan (Epinephelus fuscoguttatus) terhadap umpan buatan. Jurnal Penelitian Perikanan Indonesia, 16(1), 75-81.

Sarianto, D., Simbolon, D., \& Wiryawan, B. (2017). Dampak Pertambangan
Nikel Terhadap Daerah

Penangkapan Ikan di Perairan

Kabupaten Halmahera Timur. Jurnal Ilmu Pertanian Indonesia, 21(2), 104-113.

Wudianto, W., Mahiswara, M., \& Linting, M. (2017). Pengaruh ukuran mata pancing rawai dasar terhadap hasil tangkapan. Jurnal Penelitian Perikanan Indonesia, 1(1), 58-67. 